\title{
Perspectivas de Profissionais sobre a Comunicaçáo Multimodal no Desenvolvimento de um Sujeito com Surdocegueira ${ }^{1}$
}

\author{
Professional Perspectives on Multimodal Communication in the \\ DEVELOPMENT OF THE SUBJECT WITH DEAFBLINDNESS
}

\author{
Simara Pereira da MATA² \\ Karen Regiane SORIANO ${ }^{3}$ \\ Jáima Pinheiro de OLIVEIRA ${ }^{4}$
}

RESUMO: A comunicação é a base para todo o processo de ensino e aprendizagem de qualquer pessoa. Para o sujeito com surdocegueira, especialmente a de natureza congênita, é um desafio permanente que exige dos profissionais conhecimentos específicos, atuação adequada e bem fundamentada. Dessa forma, este estudo teve como objetivo identificar, na perspectiva de profissionais que atuaram com um sujeito com surdocegueira congênita, aspectos do uso de vias remanescentes simultâneas ou isoladas, para o estabelecimento da comunicação. Para tanto, considerando os princípios de uma pesquisa qualitativa do tipo descritiva, utilizou-se como procedimento de coleta de dados entrevistas semiestruturadas. As entrevistas foram transcritas na íntegra e tratadas a partir de seu conteúdo para a obtenção de subtemas que foram, posteriormente, agrupados e convertidos em categorias. Especificamente para essa análise, a categoria apresentada foi a de Comunicaçáo Multimodal. A análise de dados permitiu identificar as perspectivas dos profissionais em relação ao uso de vias remanescentes simultâneas ou isoladas, para favorecer o estabelecimento de uma comunicação. De modo geral, observou-se que as perspectivas dos participantes estiveram relacionadas à combinação nas formas de antecipação das atividades e/ou ações por meio da utilização de diferentes vias sensoriais, com predominância dos sentidos gustativos e olfativos, enquanto o proprioceptivo e o cinestésico foram descritos em menor proporção. Além disso, os relatos indicaram tentativas de associação entre objetos concretos e sinais, buscando, assim, de acordo com os participantes, uma comunicaçáo em nível menos elementar.

PALAVRAS-CHAVE: Educação Especial. Inclusão educacional. Comunicação sensorial.

\begin{abstract}
Communication is the basis for any person's teaching and learning process. For the deafblind subject, especially of the congenital nature, it is a permanent challenge that demands of the professionals a specific knowledge, adequate and well-founded performance. Thus, this study aimed to identify, from the perspective of professionals who worked with a subject with congenital deafblindness, aspects of use of the remaining pathways, simultaneous or isolated, for the establishment of communication. For that, based on the principles of a qualitative descriptive research, the semi-structured interview procedure was used as data collection. The interviews were transcribed in full and treated from their content to obtain subthemes that were later grouped and converted into categories. Specifically for this analysis, the category presented was the Multimodal Communication. Data analysis allowed to identify the professionals' perspectives regarding the use of simultaneous or isolated remnant pathways, in order to favor the establishment of a communication. In general, it was observed that the participants' perspectives were related to the combination of ways of anticipating activities and/or actions through the use of different sensory pathways, with a predominance of gustatory and olfactory senses, while proprioceptive and kinesthetic were described in a smaller proportion.
\end{abstract}

KEYWORDS: Special Education. Educational Inclusion. Sensorial communication.

\footnotetext{
${ }^{1}$ https://doi.org/10.1590/1980-54702021v27e0003

${ }^{2}$ Doutoranda em Educação. Universidade Estadual Paulista “Júlio de Mesquita Filho” (UNESP). Marília / São Paulo / Brasil. E-mail: simaraps@yahoo.com.br. ORCID: https://orcid.org/0000-0001-9178-3749

${ }^{3}$ Doutoranda em Educação. Universidade Estadual Paulista “Júlio de Mesquita Filho" (UNESP). Marília / São Paulo / Brasil. Bolsista do Conselho Nacional de Desenvolvimento Científico e Tecnológico (CNPq). Docente Substituta do Departamento de Educação Especial da UNESP. Marília / São Paulo / Brasil. Docente do Centro Universitário de Adamantina (UNIFAI). Adamantina / São Paulo / Brasil. E-mail: karenrsoriano@gmail.com. ORCID: https://orcid.org/0000-0003-3109-4436

${ }^{4}$ Docente do Departamento de Administração Escolar da Faculdade de Educação da Universidade Federal de Minas Gerais (UFMG). Belo Horizonte / Minas Gerais / Brasil. Docente Permanente Voluntária do Programa de Pós-Graduação em Educação da Universidade Estadual Paulista "Júlio de Mesquita Filho" (UNESP). Marília / São Paulo / Brasil. E-mail: jaimafono@gmail. com. ORCID: https://orcid.org/0000-0002-0156-3804
} 


\section{INTRODUÇÁo}

Consideramos que a escola regular deve ser um dos espaços responsáveis por proporcionar ao aluno com surdocegueira a ampliação do conhecimento de mundo e das relaçóes interpessoais, por meio de um trabalho com estratégias diferenciadas e sistematizadas que preconizem as suas potencialidades, independentemente de suas condiçôes (Maia et al., 2010).

Com essa perspectiva e de modo a contribuir para a produção científica na área de Educaçáo Especial, este estudo teve como objeto a surdocegueira, temática consideravelmente restrita, se comparada aos estudos envolvendo outras condiçóes de desenvolvimento (Araóz \& Costa, 2008; Glat et al.; 2014; Masini, 2011; Santos \& Evaristo, 2015).

De acordo com Cader-Nacimento e Costa (2010), a surdocegueira é conceituada como o comprometimento, em diferentes graus, dos sentidos receptores à distância (audiçấo e visão). A combinação desses comprometimentos pode acarretar sérios problemas de comunicação, mobilidade, informação e, consequentemente, a necessidade de estimulação e de atendimentos educacionais específicos. (p. 18)

Em geral, concorda-se que a associação da perda auditiva e visual, independentemente do grau de privação, gera limitaçóes nas respostas a estímulos externos, comunicação e interação social e, ainda, comprometimentos de caráter emocional, físico e educacional (CaderNascimento \& Costa, 2010; Maia et al., 2009; McInnes, 1999; Reyes, 2004). A associação das privaçóes em limiares mais altos, embora relativamente rara, como a surdocegueira total, acarreta maiores implicaçóes. No entanto, essas implicaçóes dependerão de outros fatores como: o período de surgimento da deficiência, a causa e, principalmente, as intervençóes e os atendimentos específicos na área da educação (Cader-Nascimento \& Costa, 2010).

Dentro dessa combinaçáo, temos os casos de surdocegueira congênita e as condiçóes adquiridas. Referimo-nos à condição congênita quando o indivíduo nasce ou a adquire antes da apropriação de uma linguagem simbólica; e a condição adquirida quando o indivíduo adquire a surdocegueira após a apropriação de uma linguagem simbólica, seja ela na modalidade oral e/ou visoespacial (Costa, 2014; Reyes, 2004).

A literatura especializada indica que, para as crianças com surdocegueira, especialmente a de natureza congênita, as experiências que envolvem o processo de aquisição e desenvolvimento da linguagem, a comunicação, a informação, a educação e a vida social são os maiores desafios (Cormedi, 2011; Miles \& McLetchie, 2008). Ainda sobre esse aspecto, Cormedi (2011) enfatizou que as dificuldades de maior complexidade para uma pessoa com surdocegueira congênita seriam as de comunicação, desenvolvimento da linguagem e, consequentemente, da aprendizagem.

Nesse sentido, a observação do comportamento da criança com surdocegueira e suas açóes comunicativas é um ponto de extrema relevância, pois, a partir dela, o adulto pode manter consistência em suas respostas e favorecer o estabelecimento de uma comunicação efetiva e autônoma. Nessas oportunidades, as possibilidades de aquisiçấo da linguagem serão potencializadas, quanto maior for o tempo de exposição em situaçôes efetivas de comunicação com parceiros eficientes (Viñas, 2004). 
As formas de comunicação são específicas, conforme as características de cada sujeito com surdocegueira, mas, para que haja sucesso, é fundamental a presença de parceiros que sejam sensíveis e receptíveis aos indícios que a criança oferece. Nesses casos, o processo de comunicação inicia-se com formas mais elementares como toque, expressóes e movimentos corporais. À medida que a criança demonstra compreensão e fornece respostas, essa comunicação poderá ser ampliada com formas mais abstratas e simbólicas (Costa, 2014).

Diferentemente das crianças sem limitaçóes sensoriais, nas quais o processo de aquisição de linguagem ocorre de forma natural por meio da comunicação e da interação, as crianças com surdocegueira precisam de um ensino sistematizado para o desenvolvimento da comunicação (McLetchie \& Riggio, 2002; Reyes, 2004). Além disso, necessitam de demasiada motivação para estabelecer contato com o mundo exterior, já que a surdocegueira afeta de forma significativa a habilidade em interagir com o meio (Amaral, 2002). Para as crianças com essa condição, a interação e a comunicação devem ocorrer pelos sentidos proximais e pelos sentidos remanescentes visuais e/ou auditivos se tiverem (Viñas, 2004).

Desse modo, considerando que a comunicação será a chave para todo o desenvolvimento e os processos de ensino e de aprendizagem, é fundamental que os profissionais que atuam com sujeitos com surdocegueira, especialmente a congênita, busquem possibilidades e forneçam suporte para o seu desenvolvimento por meio do uso de diferentes sistemas ${ }^{5}$ que englobem ou não o uso da fala e/ou da Língua de Sinais na modalidade visual ou tátil (Amaral, 2002). Esses diferentes sistemas de comunicação podem ser considerados Comunicação Suplementar e/ou Alternativa (CSA), subárea da Tecnologia Assistiva, que engloba, também, adaptaçóes, ferramentas e equipamentos especiais em diferentes áreas do desenvolvimento (motora: de acesso a computadores, de postura, dentre outros) e aciona diferentes possibilidades nos contextos de inclusão social e escolar (Braccialli, 2007; Deliberato, 2007).

De acordo com Von Tetzchener (2018), a CSA, uma forma de comunicar-se com o uso de recursos tais como imagens, símbolos gráficos e outros, oferece às crianças com necessidades complexas de comunicação e comprometimento motor possibilidades de expressar-se, o que é fundamental para sua participação social, aprendizagem e para o próprio desenvolvimento linguístico. Em relação ao desenvolvimento da CSA, Von Tetzchner et al. (2005) explicam que ele ocorre de maneira bastante diferente do desenvolvimento linguístico natural; contudo, o objetivo final é o de que as crianças usuárias de sistemas alternativos de comunicação consigam, assim como os falantes (orais ou em sinais), se comunicar com os seus pares e adultos sobre diferentes assuntos.

São muitos os desafios no processo de aquisição da linguagem dos sujeitos que precisam de um sistema alternativo de comunicação, especialmente voltados à diferença em relação ao input (visual e gestual, dentre outros) de linguagem com que eles recebem as informaçóes; a necessidade de uma comunicação multimodal e a desvinculação dessa linguagem de um sistema linguístico natural. Em relação a esse último desafio, os interlocutores que favorecem esse

${ }^{5}$ De acordo com Cader-Nascimento e Costa (2010), os principais sistemas alternativos de comunicação para a pessoa com surdocegueira são: Língua de sinais tátil, língua de sinais adaptada (redução do campo de articulação, por exemplo), sistema Braille (convencional e digital), escrita ampliada, escrita alfabética na palma da mão, tadoma e objetos de referência. 
sistema também se sentem desafiados, por não terem uma estrutura (forma, função e uso) a ser priorizada (Deliberato et al., 2014).

A comunicação multimodal ou multimodalidade, caracterizada pela combinação de diferentes formas de comunicação, de maneira simultânea ou sequencial, para veiculação de informaçóes, é, de acordo com Nunes (2003), uma das características marcantes da CSA. Alguns estudos apontam que a multimodalidade dentro do processo de desenvolvimento da comunicação de crianças com surdocegueira é bastante adotada, já que, com a privação dos sentidos receptores a distância, deve-se recorrer, potencialmente, às formas alternativas de comunicação, por meio dos sentidos remanescentes, a fim de que consigam estabelecer laços com o meio (Maia \& Araóz, 2001; Reyes, 2004). Assim, o processo de aprendizagem da comunicação para as crianças com surdocegueira exige apoio especializado e condiçóes educacionais planejadas e de qualidade (Cader-Nascimento \& Costa, 2010).

De acordo com Villas-Boas (2014), são escassas as informações sobre as formas de aprendizagem, atenção e comunicação de crianças com surdocegueira congênita e deficiência múltipla sensorial; logo, conhecer as formas de comunicação desses sujeitos e as suas características é fundamental para uma assistência profissional mais efetiva.

Hersh (2013), a partir de entrevistas realizadas com surdocegos de seis países, discutiu questóes relacionadas à comunicação, à independência e ao isolamento. Os dados obtidos evidenciaram a importância do desenvolvimento de um sistema que permitisse aos sujeitos se comunicarem efetivamente com outras pessoas, pois a dificuldade na comunicaçáo, mesmo para aqueles com um grau menor de perda visual e/ou auditiva, configurava-se como um grande obstáculo para a participação social, levando-os ao isolamento. Os dados obtidos no estudo de Hersh (2013) destacaram, ainda, o fato de, devido à necessidade de apoio para comunicação e mobilidade, muitos profissionais e/ou acompanhantes de pessoas com surdocegueira tirarem todas as possibilidades de independência e de vida ativa desses sujeitos. Maguvhe (2014) investigou as perspectivas de professores de surdocegos acerca da elaboração do currículo, a implementação e o envolvimento da família no processo de escolarização. Sobre o primeiro aspecto investigado, os participantes indicaram grande distância entre o currículo para os alunos surdocegos nas escolas especiais e o currículo nacional. Alguns fatores foram apontados como possibilidade de melhora no atendimento escolar desse público, especialmente para o desenvolvimento da comunicaçáo e, consequentemente, para a aprendizagem dos demais conteúdos escolares, como a matemática e as ciências naturais, por exemplo. Os fatores foram: profissionais de apoio com formação na área, formação regular em serviço para os professores e provisão de recursos adequados e suficientes para o ensino dos alunos com surdocegueira.

Em relação ao envolvimento da família no processo de escolarização dos alunos com surdocegueira, Maguvhe (2014) afirmou que, embora os professores participantes do estudo destacassem conhecimento acerca da importância dessa participação, especialmente para o estabelecimento de formas de comunicação, na prática o contato era restrito. Os participantes apontaram como uma possibilidade a criação de um grupo de pais que impulsionassem a participação de outras famílias a partir de açóes e de intervençóes educativas apropriadas.

$\mathrm{Na}$ mesma perspectiva da educação escolar para alunos com surdocegueira, Charles (2014), a partir de um estudo descritivo realizado em uma escola de surdocegos no Quênia, 
o qual teve como objetivo investigar as características dos professores que atuavam com esse grupo, afirmou que a competência dos professores relacionada ao conhecimento e à experiência na área, interferem positivamente no apoio ao aluno surdocego e, por conseguinte, no seu desenvolvimento. $\mathrm{O}$ autor destacou como fundamental a habilidade do professor que atua com alunos com surdocegueira em avaliar, interpretar e responder às formas pré-simbólicas que um aluno surdocego pode utilizar para se comunicar, a fim de aumentar o seu desenvolvimento de comunicação e interação social.

Considerando a escassez de estudos nacionais com essa temática e os pontos até aqui abordados, a problematização desta pesquisa girou em torno da seguinte pergunta: Quais seriam as perspectivas de profissionais que atuaram com um sujeito com surdocegueira total congênita, acerca do uso da comunicação multimodal em diferentes contextos de atendimento?

De modo a desenvolver parte dessa problematização e com o objetivo de traçar um panorama científico nacional de produção de teses e de dissertaçóes sobre a surdocegueira, realizamos um levantamento das pesquisas finalizadas até o primeiro semestre de 2019. Para tanto, utilizamos, como base, estudos que recensearam as produçóes científicas sobre surdocegueira em períodos distintos desde a defesa da primeira dissertação da área no ano de 1999 (Araóz \& Costa, 2008; Masini, 2011; Santos \& Evaristo, 2015) e dados da Biblioteca Digital de Teses e Dissertaçóes, no portal de teses da Coordenação de Aperfeiçoamento de Pessoal de Nível Superior (CAPES) a partir do descritor "surdocegueira".

Os resultados obtidos foram: 27 pesquisas produzidas em programas de PósGraduação em nível de Mestrado e 11 em nível de Doutorado, o que evidenciou ainda mais a relevância científica do presente estudo, em relação às necessidades investigativas na área da Educação Especial. Os estudos encontrados destacaram, inclusive, a necessidade emergente dessas investigaçóes, considerando aspectos do desenvolvimento dos sujeitos com surdocegueira, especialmente em relação ao desenvolvimento da comunicação.

Diante desse panorama, este estudo possui características que lhe conferem elementos de inovação nessa produção, com especial atenção aos aspectos de desenvolvimento da comunicação do sujeito-alvo da pesquisa desenvolvida. Para reforçar esse aspecto, mencionamos que esta pesquisa também inaugurou a temática no Programa de Pós-Graduação em Educação da Faculdade de Filosofia e Ciências (FFC) da Universidade Estadual Paulista (UNESP), Campus Marília, São Paulo.

Não podemos conferir ou inferir traços de completo ineditismo em razão de considerarmos a produção internacional como importante alavanca para a área e, também, para esta análise, ainda que o nosso foco em relação ao estado da arte tenha sido a produção nacional, respeitando-se os aspectos socioculturais e a diversidade da pesquisa científica brasileira. Por fim, considerando que, em relação à educação, a comunicação é fundamental para o desenvolvimento e os processos de ensino e de aprendizagem (Oliveira et al., 2017) e, no caso de alunos com surdocegueira, um desafio permanente (McLetchie \& Riggio, 2002), bem como a prioridade no processo educacional das pessoas com surdocegueira deve ser a potencialização das habilidades comunicativas (Reyes, 2004), este estudo, realizado com profissionais que atuaram com um sujeito com surdocegueira congênita teve como objetivo identificar, na perspectiva 
desses profissionais, aspectos do uso de vias remanescentes simultâneas ou isoladas, para o estabelecimento da comunicação.

\section{Método}

O presente estudo configura-se como uma pesquisa de natureza qualitativa, do tipo descritivo, caracterizada por Godoy (1995) como uma investigação que surge de questionamentos e focos amplos de interesse, nos quais os dados são apresentados de forma descritiva e pretendem atingir a compreensão de fenômenos, com base em diferentes perspectivas dos sujeitos envolvidos.

Participaram deste estudo sete profissionais que atuaram com um sujeito que se tornou surdocego total nos primeiros meses de vida em decorrência de complicaçóes por prematuridade extrema, denominado ficticiamente de Mike. Esses profissionais atuavam em três instituições nas quais Mike foi atendido, formalmente, dos primeiros anos de vida até os 17 anos, a saber: Centro de Especialidades, Programa de Equoterapia e a escola regular.

O Quadro 1 apresenta a caracterização desses profissionais participantes do estudo, por ordem sequencial de atendimento ao sujeito.

\section{Quadro 1}

Dados de perfil dos participantes

\begin{tabular}{|c|c|}
\hline Identificação & Caracterizaçáao \\
\hline Beatriz & $\begin{array}{l}\text { Formação: Fonoaudiologia; Especialização em Linguagem; e Mestrado em Linguagem. } \\
\text { Área de atuaçáo: Fonoaudióloga em uma clínica e no Programa de Equoterapia. } \\
\text { Tempo de atuação na área: } 15 \text { anos. } \\
\text { Atuação com Mike: profissional de referência, durante o período em que Mike passou por atendimento } \\
\text { no programa de equoterapia, aproximadamente dos } 8 \text { aos } 12 \text { anos de idade. }\end{array}$ \\
\hline Cláudia & $\begin{array}{l}\text { Formação: Magistério; Pedagogia; Especialização em Educação Especial/Inclusiva; e Especialização em } \\
\text { Tradução/Interpretação de Libras. } \\
\text { Área de Atuação: professora de Atendimento Educacional Especializado e Intérprete Educacional de } \\
\text { Libras. } \\
\text { Tempo de atuação na área: } 15 \text { anos na educação em geral e } 6 \text { anos na Educação Especial. } \\
\text { Atuação com Mike: intérprete educacional de Libras na sala que Mike frequentava e professora do AEE } \\
\text { de Mike no terceiro, quarto e quinto ano do Ensino Fundamental na escola regular. }\end{array}$ \\
\hline Heloá & $\begin{array}{l}\text { Formação: Educação Física; Pedagogia; Especialização em Psicopedagogia. } \\
\text { Área de atuação: professora de Educação Física. } \\
\text { Tempo de atuação na área: } 25 \text { anos. } \\
\text { Atuação com Mike: professora de Educação Física de Mike na escola regular do terceiro ao quinto ano } \\
\text { do Ensino Fundamental. }\end{array}$ \\
\hline Michele & $\begin{array}{l}\text { Formaçãa: Magistério; Pedagogia; Especialização em Gestão Escolar. } \\
\text { Área de atuaçáo: professora de Educação Básica. } \\
\text { Tempo de atuação na área: } 13 \text { anos. } \\
\text { Atuação com Mike: professora de classe comum de Mike, durante o quarto e o quinto ano do Ensino } \\
\text { Fundamental na Escola Regular. }\end{array}$ \\
\hline Henrique & $\begin{array}{l}\text { Formação: Letras; Pedagogia; Artes Visuais; Especialização em Alfabetização. } \\
\text { Área de atuaçáo: professor de artes e português. } \\
\text { Tempo de atuação na área: } 8 \text { anos. } \\
\text { Atuação com Mike: professor de arte de Mike na escola regular, durante o terceiro e o quinto ano do } \\
\text { Ensino Fundamental. }\end{array}$ \\
\hline
\end{tabular}




\begin{tabular}{|l|l|}
\hline \multicolumn{1}{|c|}{ Identificaçáo } & \multicolumn{1}{c|}{ Caracterizaçáo } \\
\hline \multirow{3}{*}{ Giovana } & $\begin{array}{l}\text { Formação: Magistério. } \\
\text { Área de atuação: monitora }\end{array}$ \\
& $\begin{array}{l}\text { Tempo de atuaçáo na área: } 5 \text { anos. } \\
\text { Atuação com Mike: monitora de Mike, durante o quarto e o quinto ano do Ensino Fundamental na } \\
\\
\text { escola regular. }\end{array}$ \\
\hline
\end{tabular}

O procedimento de coleta de dados adotado nesta investigação foi o de entrevista semiestruturada, com um roteiro contendo perguntas abertas. Durante a realização da entrevista, houve alteraçóes na ordem das perguntas e inclusão de questôes complementares, visando o melhor entendimento do fenômeno estudado (Manzini, 2012). Após a elaboração, os roteiros, com o objetivo de adequaçáo do instrumento de coleta, foram enviados para apreciaçáo de juízes externos, reelaborados de acordo com as sugestóes propostas e segunda apreciação desses juízes (Manzini, 2004).

Participaram como juízes três profissionais da área da Educação Especial - duas pedagogas e uma fonoaudióloga - todos com experiência acadêmica na realização de entrevistas. Além dos roteiros, os juízes receberam uma breve descriçáo da pesquisa, almejando a adequação desse roteiro em relação ao objetivo do estudo, da linguagem utilizada nele, da forma e da sequência das perguntas, conforme orientado por Manzini (2003).

As entrevistas foram realizadas em dias previamente agendados com os participantes, em seus respectivos ambientes de trabalho. Os áudios das entrevistas foram gravados e posteriormente transcritos, na íntegra. Após a transcrição, os dados passaram por adequaçóes e ajustes ortográficos (Manzini, 2012, 2014).

Neste texto, utilizamos itálico para as falas dos relatos dos profissionais na apresentação dos resultados. Foram utilizados, nas transcriçôes, os seguintes sinais: reticências entre colchetes, para indicar supressóes no início, meio e/ou final dos trechos; parênteses, para observaçóes e comentários feitos pela pesquisadora; e aspas, para os momentos nos quais o participante empregou a fala de outra pessoa em sua própria fala.

Após a transcrição, os dados foram tratados a partir de seu conteúdo, com base em Bardin (2011). Adotou-se como critério para seleção dos dados a temática "comunicação" e, em seguida, foram estabelecidos subtemas. Para Bardin (2011), a expressão análise de conteúdo compreende

[u]m conjunto de técnicas de análises das comunicaçôes visando obter, por procedimentos, sistemáticos e objetivos de descrição do conteúdo das mensagens, indicadores (quantitativos ou não) que permitam a inferência de conhecimentos relativos às condiçôes de produção/recepção (variáveis inferidas) destas mensagens. (p. 42)

Assim, para o processo de obtenção de temas, foram considerados, inicialmente, os relatos que indicavam as perspectivas dos profissionais, isoladas (um único participante)

\footnotetext{
${ }^{6}$ Monitores no município cujo estudo foi realizado são profissionais que atuam com os estudantes do público-alvo da Educaçấo Especial e têm como função geral executar atividades relacionadas às práticas de estimulação, apoio, avaliação, registro, sob a supervisão e a orientação de docentes, do professor coordenador e do núcleo gestor da unidade educacional.
} 
ou recorrentes (mais de um participante), sobre aspectos do desenvolvimento da comunicação, no sujeito com surdocegueira congênita. Os relatos foram classificados em subtemas, em função dos aspectos emergidos nesse primeiro momento. Em seguida, esses subtemas foram agrupados e convertidos em cinco categorias ${ }^{7}$, a saber: Primeiras tentativas de comunicação; Desenvolvimento de conceitos; Comunicação multimodal; Linguagem receptiva; e Linguagem expressiva. Todas essas categorias encontram-se detalhadas em Mata (2017), tanto em relação às suas definiçóes quanto aos seus resultados. Para a análise deste artigo, foi priorizada a categoria de Comunicação Multimodal.

\section{Resultados E disCUSSĀO: COMUNICAÇÁO MULTIMODAL}

Uma das possibilidades de criação de oportunidades para as crianças com surdocegueira congênita é a integração dos diferentes caminhos sensoriais (Turiansky \& Bove, 1991). Logo, nessa categoria, foram englobados os relatos dos profissionais, conforme o Quadro 2, que explicitaram o uso de vias remanescentes simultâneas ou isoladas, para favorecer o estabelecimento de uma comunicação. Foram considerados, ainda, relatos que apontaram esse uso, associado a um dos aspectos (sinais isolados ${ }^{8}$ ) da Língua Brasileira de Sinais (Libras).

\section{Quadro 2}

Relatos que exemplificam a categoria "Comunicação multimodal"

\begin{tabular}{|c|c|c|}
\hline Participante & Exemplos de relatos & Ideias subjacentes \\
\hline $\begin{array}{l}\text { Beatriz - } \\
\text { Fonoaudióloga } \\
\text { do Programa } \\
\text { de Equoterapia }\end{array}$ & 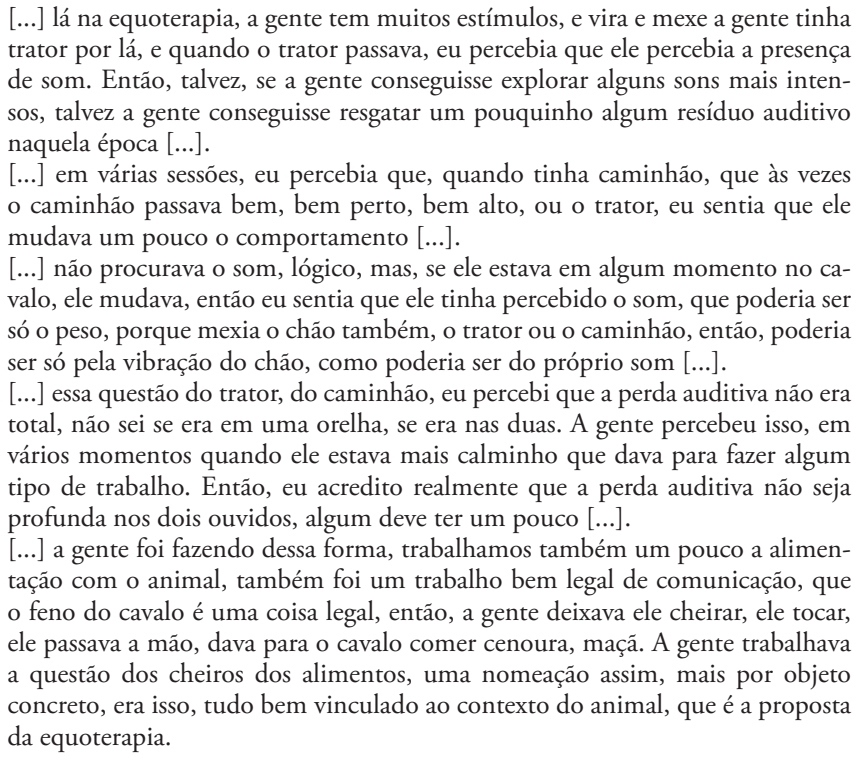 & $\begin{array}{l}\text { Utilização de possíveis } \\
\text { resíduos auditivos. } \\
\text { Utilização simultânea } \\
\text { dos sentidos olfativo } \\
\text { e tátil. }\end{array}$ \\
\hline
\end{tabular}

\footnotetext{
${ }^{7}$ Essas categorias e as suas respectivas classificaçōes passaram por apreciação de dois juízes externos com formação na área de Educação Especial, em nível de Doutorado.

${ }^{8}$ De acordo com Cormedi (2012), sinais isolados funcionam como palavras isoladas; embora não estejam organizados conforme a estrutura linguística da língua de sinais, conseguem, de forma contextualizada, expressar o significado do todo.
} 


\begin{tabular}{|c|c|c|}
\hline Participante & Exemplos de relatos & Ideias subjacentes \\
\hline $\begin{array}{l}\text { Cláudia - } \\
\text { Professora do } \\
\text { AEE }\end{array}$ & 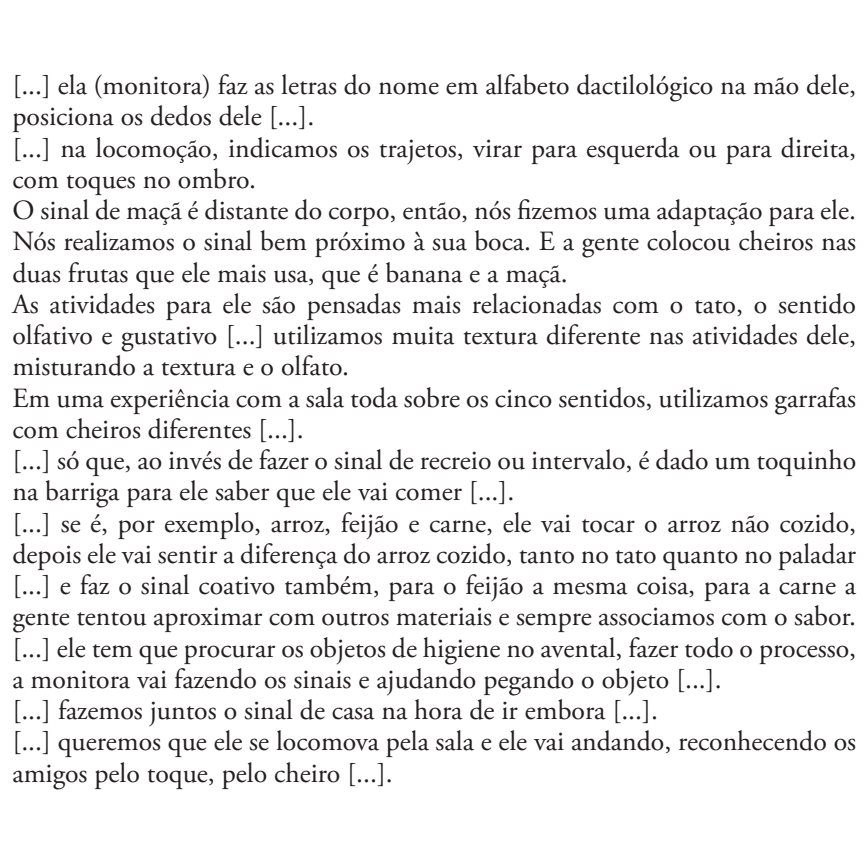 & $\begin{array}{l}\text { Introdução de aspectos } \\
\text { da Língua de Sinais } \\
\text { com o alfabeto dactilo- } \\
\text { lógico. } \\
\text { Utilizaçáo dos sentidos } \\
\text { proprioceptivo e tátil. } \\
\text { Introdução de aspectos } \\
\text { da Língua de Sinais } \\
\text { com adaptaçáo de sinais } \\
\text { isolados associada ao } \\
\text { sentido olfativo. } \\
\text { Utilizaçáo dos sentidos } \\
\text { olfativo e tátil. } \\
\text { Utilização do sentido } \\
\text { olfativo de maneira } \\
\text { isolada. } \\
\text { Utilização dos sen- } \\
\text { tidos tátil, olfativo e } \\
\text { gustativo de maneira } \\
\text { associada. } \\
\text { Utilização de aspectos } \\
\text { da Língua de Sinais por } \\
\text { meio de sinais coativos. } \\
\text { Utilizaçáo dos sentidos } \\
\text { tátil e olfativo para } \\
\text { reconhecimento de } \\
\text { pessoas. }\end{array}$ \\
\hline $\begin{array}{l}\text { Michele - } \\
\text { Professora de } \\
\text { classe comum }\end{array}$ & $\begin{array}{l}\text { Quando a gente vai fazer o cardápio tátil, ele toca no prato, toca no talher, } \\
\text { exploramos tanto o paladar quanto o aroma. } \\
\text { No cardápio e em atividades que vai usar essência ou até mesmo som, ele cor- } \\
\text { responde, se a gente está com um chocalho bem próximo ele vira, ele sorri [...]. }\end{array}$ & $\begin{array}{l}\text { Utilização dos sen- } \\
\text { tidos tátil, olfativo e } \\
\text { gustativo de maneira } \\
\text { associada. } \\
\text { Utilizaçáo de possíveis } \\
\text { resíduos auditivos. }\end{array}$ \\
\hline $\begin{array}{l}\text { Heloá - } \\
\text { Professora } \\
\text { de Educação } \\
\text { Física }\end{array}$ & 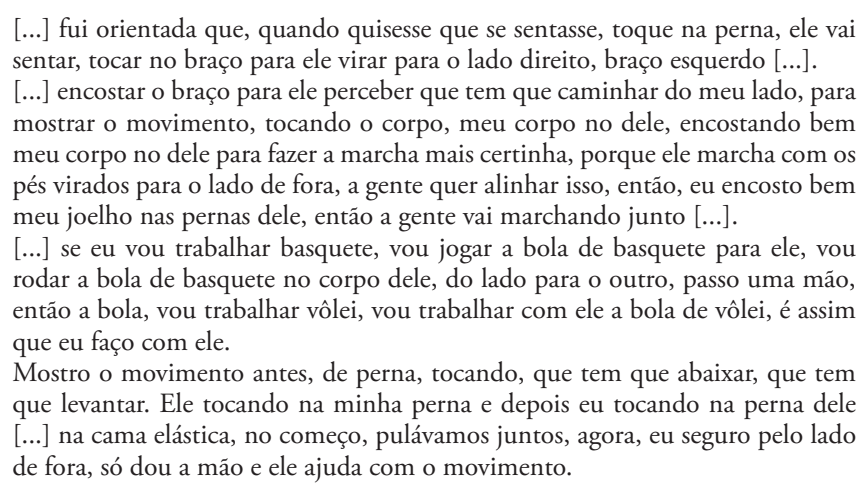 & $\begin{array}{l}\text { Utilização dos sentidos } \\
\text { proprioceptivo e tátil. } \\
\text { Utilizaçáo do sentido } \\
\text { cinestésico. } \\
\text { Utilizaçáo dos sentidos } \\
\text { proprioceptivo e cines- } \\
\text { tésico. }\end{array}$ \\
\hline $\begin{array}{l}\text { Henrique - } \\
\text { Professor de } \\
\text { Arte }\end{array}$ & $\begin{array}{l}\text { Por exemplo, em relação a sentar, dar um toque nas pernas, para levantar tam- } \\
\text { bém [...]. } \\
\text { Sobre o trabalho com as cores, a turma toda estava explorando e pintando com } \\
\text { as cores quentes e frias, para ele, fizemos adaptaçóes com essências, para associar } \\
\text { a cor com diferentes essências. Nas cores frias, era um cheiro mais ameno, mais } \\
\text { tranquilo; nas cores quentes, era um cheiro mais forte. Ele gosta, foi assim, bem } \\
\text { bacana, que ele gostou de sentir os diferentes cheiros. Teve um que ele acabou, } \\
\text { eu nâo lembro qual, mas que ele segurou, ficou um tempinho com ele nas máos. }\end{array}$ & $\begin{array}{l}\text { Utilização dos sentidos } \\
\text { proprioceptivo e tátil. } \\
\text { Utilizaçáo do sentido } \\
\text { olfativo. }\end{array}$ \\
\hline
\end{tabular}




\begin{tabular}{|c|c|c|}
\hline Participante & Exemplos de relatos & Ideias subjacentes \\
\hline $\begin{array}{l}\text { Giovana - } \\
\text { Monitora }\end{array}$ & $\begin{array}{l}\text { [...] eu pego na mão dele, chego aqui no portão, eu coloco a mochila nas costas } \\
\text { com ele e já faço o sinal de estudar. } \\
\text { "Ele entra, eu toco no ombro dele aqui (aponta para o seu ombro), e aí ele já } \\
\text { tira a mochila, tem dia que eu consigo... que ele fica com a mochila ali na mão, } \\
\text { mas tem dia que ele solta. } \\
\text { Descemos para o refeitório para comer uma maçã, por exemplo, então, a gente } \\
\text { faz o sinal de maçã ali na sala, mostra a rotina, apresenta a rotina ali toda para } \\
\text { ele, pego a maçá e vai para o refeitório comer a maçá. Ele se senta ali no refei- } \\
\text { tório, eu apresento a maçá de novo para ele, a maçâ inteira, faço ele manusear } \\
\text { a maçã, rodo, mostro que tem o cabinho embaixo, tem o negocinho em cima, } \\
\text { embaixo, o cabinho em cima, cheira [...]. } \\
\text { Me comunico com ele com toques no ombro, na perna, e ficar às vezes por } \\
\text { detrás, quando quero fazer algum movimento com ele, por exemplo, para ele } \\
\text { agachar, eu vou deitando meu corpo com ele, agachando com ele. }\end{array}$ & $\begin{array}{l}\text { Utilização de aspectos } \\
\text { da Língua de Sinais por } \\
\text { meio de sinais coativos. } \\
\text { Utilizaçáo dos sentidos } \\
\text { proprioceptivo e tátil. } \\
\text { Utilizaçáo dos sentidos } \\
\text { proprioceptivo e cines- } \\
\text { tésico. }\end{array}$ \\
\hline
\end{tabular}

Observa-se que, de modo geral, as perspectivas dos participantes, nessa categoria, estiveram relacionadas à combinação nas formas de antecipação das atividades e/ou açóes por meio da utilização de diferentes vias sensoriais. As participantes Beatriz e Michele apontaram percepção de possibilidade de uso de um sentido distal, a audição, mas sem indícios de uso funcional. Os sentidos gustativos e olfativos estiveram presentes na maior parte dos relatos, enquanto o proprioceptivo e o cinestésico, em menor proporção. Há relatos que revelaram tentativas de associação entre objetos concretos e sinais, buscando, assim, uma comunicação em um nível menos elementar.

Em consonância aos dados apresentados que evidenciam o emprego dos sentidos para o desenvolvimento da comunicação, Maia et al. (2009) destacaram que as experiências táteis são formas de adquirir informaçôes sobre o mundo; a utilização do canal olfativo auxilia na interpretação do meio e na atribuição de significados; o olfato e o paladar ajudam a compreender melhor o mundo, especialmente por ser o olfato um sentido de recepção da informação à distância; e, por fim, o uso dos sentidos cinestésico e proprioceptivo favorecem a organização corporal e os movimentos.

Especificamente no caso de Mike, os relatos de Beatriz e Michele pareceram ressaltar a possibilidade de um resíduo auditivo. ${ }^{9}$ Quanto a essa questão, Amaral (2002) afirmou que o uso da audição residual é muito importante para a criança com surdocegueira complementar as informaçóes recebidas pelos outros sentidos. A autora defende que o papel do profissional, aludindo especificamente ao professor, é fornecer todos os meios possíveis de estímulos sensoriais, tornando-os significativos e integrando-os aos outros sentidos; sublinha que o conhecimento das formas de potencialização do uso dos resíduos auditivos deve ser considerado, na formação dos profissionais que atuam com pessoas com surdocegueira (Amaral, 2002). Nota-se, ainda, nos relatos dos participantes, perspectivas positivas em relação às formas alternativas de comunicação envolvendo o uso dos sistemas gustativo, olfativo, cinestésico, proprioceptivo e tátil.

De maneira enfática, pesquisadores defendem ser primordial, na trajetória inicial do desenvolvimento da comunicação e da linguagem para crianças com surdocegueira, o uso de todas as formas possíveis e recursos para comunicação, já que somente a fala ou a língua

\footnotetext{
${ }^{9}$ Nos registros do sujeito, não foram encontrados exames audiológicos e, nos relatos da mãe usados para contextualização do caso, não foram observadas quaisquer referências à possibilidade de existência de resíduos auditivos.
} 
de sinais, mesmo quando há resíduos funcionais, em muitos casos, não é suficiente (CaderNascimento \& Costa, 2003; Turiansky \& Bove, 1991). No entanto, é importante atentar para o desafio de facilitar na criança com surdocegueira o desenvolvimento da linguagem e aquisição de uma língua, geralmente a língua de $\operatorname{sinais}^{10}$ (Cormedi, 2012).

Para Cormedi (2012), a utilização de todas as formas possíveis de comunicação objetos de referência, gestos e sinais isolados - tem como objetivo "possibilitar que surdocegos possam fazer simbolizações e representações e, se possível, apoderar-se de uma língua” (p. 180).

Em relação ao emprego da língua de sinais, os participantes mencionaram a introdução de sinais isolados da Língua Brasileira de Sinais. Sobre esse aspecto, Almeida (2008) e Cader-Nascimento e Costa (2003) realizaram estudos que demonstraram possibilidades de apropriação dessa língua. Almeida (2008) descreveu a trajetória da comunicação de "J" que, de acordo com a autora, começou a perceber e estabelecer relação entre sinal e significado, a partir da persistência da mãe. Aos cinco anos de idade, aprendeu o significado do primeiro sinal "água”, após a mãe por diversas vezes, durante o banho, jogar água em seu corpo e fazer o sinal de forma coativa. Em outro momento, apresentou o mesmo sinal, ao oferecer água para tomar (Almeida, 2008).

Cader-Nascimento e Costa (2003) trataram dessa apropriação, no contexto escolar. As autoras discutiram o desenvolvimento linguístico de uma aluna com surdocegueira que manifestava vontade de ir ao banheiro, posicionando-se na sala de aula e abaixando a calça. A profissional que a acompanhava passou a observar os movimentos que antecediam essa ação e, nesse momento, realizava o sinal de banheiro, no braço da aluna, e a guiava ao banheiro. No banheiro, repetiam o sinal de forma coativa e contextualizada e, em seguida, a incentivava a fazê-lo sozinha.

Associando os dados com os estudos descritos, foi possível notar que alguns aspectos são importantes para que o sujeito com surdocegueira consiga se apropriar de um signo: que a sua introdução e utilização sejam significativas, portanto contextualizadas; que sejam efetuadas sempre da mesma forma, deixando, por exemplo, o sujeito perceber a realizaçáo do sinal pelo interlocutor e depois ser ajudado a fazê-lo; e que o sujeito seja estimulado a realizar o sinal de maneira independente.

Ainda nessa perspectiva da utilização dos sentidos remanescentes para o estabelecimento da comunicação, a participante Heloá referiu-se a formas que abordam os sistemas tátil e proprioceptivo. Os dados apresentados pela participante assemelham-se às indicaçóes de uso de movimentos coativos, descrito por Van Dijk (1968). Sobre esse aspecto, Cader-Nascimento e Costa (2010) destacaram o seguinte:

Sua abordagem parte do princípio de que as atividades/açôes propostas precisam ser realizadas em conjunto, ou seja, o mediador (professor, cuidador, pais, parentes ou amigos) e a criança devem realizar movimentos e açóes simultaneamente. (p. 43)

\footnotetext{
${ }^{10}$ Para muitas pessoas com surdocegueira, devido à ausência ou redução de percepção visual, a língua de sinais não será realizada no espaço, mas na mão (Cormedi, 2012).
} 
Ainda sobre a utilização dos sentidos tátil e proprioceptivo, a participante Heloá citou estratégias como exploração do objeto e seu movimento de forma simultânea (com a bola de basquete) e oferta de modelo de movimento (pulando na cama elástica). Turiansky e Bove (1991) salientaram que movimentos do corpo inteiro são eficazes para o fornecimento de modelos mais completos para imitação, já Andreossi et al. (2012), referindo-se à construção da consciência corporal em crianças com surdocegueira, enfatizaram que atividades lúdicas facilitam o desenvolvimento dessa consciência e a compreensão do seu corpo e dos movimentos executados por suas diferentes partes. De acordo com o autor, esse é um dos desafios para os profissionais, já que, em virtude das limitaçóes visuais e auditivas, as habilidades de imitação dos padróes de movimentos são comprometidas.

De modo geral, compreende-se que, devido aos desafios impostos pela surdocegueira, é imprescindível para o desenvolvimento da comunicação de sujeitos com essa condição recursos adequados e parceiros comunicativos eficientes. Considera-se eficaz, nesse processo, uma abordagem de comunicação baseada na multimodalidade, ou seja, por meio de estímulos dos sentidos remanescentes como olfato, paladar, proprioceptivo, cinestésico e tátil e, à medida que o sujeito responder ou fornecer indicadores de compreensão, esses interlocutores devem priorizar padronizaçóes nessa comunicação.

\section{Conclusóes}

Ao longo de todo o processo de desenvolvimento e de ensino e de aprendizagem de qualquer sujeito, a comunicação é fundamental. No caso daqueles com surdocegueira, trata-se de um desafio permanente para os diferentes profissionais (McLetchie \& Riggio, 2002). Dentro desse contexto, este estudo teve como objetivo identificar, na perspectiva de profissionais que atuaram com um sujeito com surdocegueira congênita, aspectos do uso de vias remanescentes simultâneas ou isoladas, para o estabelecimento da comunicação.

Os resultados obtidos no estudo permitiram-nos considerar alguns pontos: as perspectivas dos participantes estiveram relacionadas à combinação nas formas de antecipação das atividades e/ou açóes por meio da utilização de diferentes vias sensoriais; há a percepção de possibilidade de uso de um sentido distal, a audição, mas sem indícios de uso funcional; há presença dos sentidos gustativos e olfativos na maior parte dos relatos, enquanto o proprioceptivo e o cinestésico, em menor proporção; e há tentativas de associação entre objetos concretos e sinais, buscando, assim, uma comunicação em um nível menos elementar.

Consideramos que o estudo trouxe contribuiçôes para as pesquisas voltadas à área do desenvolvimento da comunicação e da linguagem em pessoas com surdocegueira congênita. Esperamos, desse modo, que essa contribuição se estenda a investigaçóes futuras, tendo em vista a necessidade emergente de trabalhos que abordem essa temática, especialmente no contexto das escolas de ensino regular. 


\section{REFERÊNCIAS}

Almeida, C. A. F. (2008). A aquisição da linguagem por uma surdocega pré-linguística numa perspectiva sociocognitiva-interacionista [Tese de Doutorado, Universidade de Brasília - UNB]. Repositório da UNB. https://repositorio.unb.br/bitstream/10482/5723/1/2008_CeliaAFAlmeida_reduzida.pdf

Amaral, I. (2002). A educação de estudantes portadores de surdocegueira. In E. F. S. Masini (Org.), Do sentido... pelos sentidos... para o sentido (pp. 121-144). Vetor.

Andreossi, S. C., Masini, E. S, Rosenberg, R., Callegari, R. M., Silva, M. S., Comedi, M. A., Carillo, E. P., Miranda, W. P., Olmos, H. B., \& Jacob, R. N. F. (2012). Orientação e mobilidade na educação de surdocegos congênitos. In A. M. B. Silva (Org.), Heldy meu nome: rompendo barreiras da surdocegueira (pp. 10-19). United Press.

Araóz, S. M. M., \& Costa, M. P. R. (2008). Reflexão sobre a relação existente entre pesquisas e publicaçôes sobre surdocegueira no Brasil. Revista Educação Especial, 21(32), 257-272. http:// dx.doi.org/10.5902/1984686X

Bardin, L. (2011). Análise de conteúdo. Edições 70.

Braccialli, L. M. P. (2007). Tecnologia assistiva: perspectiva de qualidade de vida para pessoa com deficiência. In R. Vilarta, G. L. Gutierrez, T. H. P. F. de Carvalho, \& A. Gonçalves (Orgs.), Qualidade de vida e novas tecnologias (pp. 105-114). Ipes.

Cader-Nascimento, F. A. A. A., \& Costa, M. P. R. (2003). Mediação pedagógica no processo de desenvolvimento da comunicação em crianças surdocegas. Temas em psicologia, 11(2), 85-96.

Cader-Nascimento, F. A. A. A., \& Costa, M. P. R. (2010). Descobrindo a surdocegueira: educação e comunicação. EDUFSCar.

Charles, C. J. (2014). Teacher characteristics in supporting deafblind learners: a case of kabarnet school for deafblind children. Journal of Education and Practice, 5(28), 184-196.

Cormedi, M. A. (2011). Alicerces de significados e sentidos: aquisição de linguagem na surdocegueira congênita [Tese de Doutorado, Faculdade de Educação da Universidade de São Paulo - USP]. Repositório da USP. https://www.teses.usp.br/teses/disponiveis/48/48134/tde-04072011-152503/publico/ MARIA_APARECIDA_CORMEDI.pdf

Cormedi, M. A. (2012). Facilitando a comunicação da criança com surdocegueira congênita: a importância do mediador. In A. M. B. Silva (Ed.), Heldy meu nome: rompendo barreiras da comunicação (pp. 171-182). United Press.

Costa, M. P. R. (2014). Surdocegueira. In M. C. Marquezine, R. M. Bustos, \& E. J. Manzini (Orgs.), Surdo, cego e surdocego frente às questöes da inclusão escolar (pp.115-132). ABPEE.

Deliberato, D. (2007). Comunicação alternativa: recursos e procedimentos utilizados no processo de inclusão do aluno com severo distúrbio na comunicação. In S. Z. Pinho, \& J. R. C. S. Saglietti (Orgs.), Núcleos de Ensino (pp. 366-378). Cultura Acadêmica.

Deliberato, D., Nunes, L. R. D. P., \& Walter, C. C. F. (2014). Linguagem e Comunicação Alternativa: caminhos para a interação e comunicação. In M. A. Almeida, \& E. G. Mendes (Orgs.), A escola e o público-alvo da Educação Especial: apontamentos atuais (pp. 197-210). M \& M.

Glat, R., Omote, S., \& Pletsch, M. D. (2014). Análise crítica da produção do conhecimento em Educação Especial. In S. Omote, A. A. S. Oliveira, \& M. C. M. Chacon (Eds.), Ciência e conhecimento em Educação Especial (pp. 25-44). Marquezine \& Manzini, ABPEE. 
Godoy, A. S. (1995). Introdução à pesquisa qualitativa e suas possibilidades. Revista de Administração de Empresas, 35(2), 57-63.

Hersh, M. (2013). Deafblind people, communication, independence, and isolation. Journal of Deaf Studies and Deaf Education, 18(4), 446-463. DOI: 10.1093 / surdo / ent022

Maguvhe, M. O. (2014). Curriculum design, implementation and parental involvement in the education of the deafblind: South African teachers' perspectives. Mediterranean Journal of Social Sciences, 5(20), 1486-1492. DOI: $10.5901 /$ mjss.2014.v5n20p1486

Maia, S. R., \& Araóz, S. M. M. (2001). A Surdocegueira: saindo do escuro. Revista Educação Especial, 17, 1-3. http://dx.doi.org/10.5902/1984686X

Maia, S. R., Araóz, S. M. M., \& Ikonomidis. V. M. (2010). Surdocegueira e Deficiência Múltipla Sensorial: sugestóes de recursos acessiveis e estratégias de ensino. Grupo Brasil de Apoio ao Surdocego e ao Múltiplo Deficiente Sensorial.

Maia, S. R., Giacomini, L., \& Araóz, S. M. M. (2009). Desenvolvimento da aprendizagem em crianças com deficiência múltipla sensorial. In M. P. R. Costa (Org.), Múltipla Deficiência Pesquisa \& Intervençâo (pp. 49-64). Pedro \& João.

Manzini, E. J. (2003). Consideraçóes sobre a elaboração de roteiro para entrevista semi-estruturada. In M. C. Marquezine, M. A. Almeida, \& S. Omote (Orgs.), Colóquios sobre pesquisa em Educação Especial (pp. 11-25). Eduel.

Manzini, E. J. (2004). Entrevista semi-estruturada: análise de objetivos e de roteiros. Artigo apresentado no 2o Seminário Internacional sobre Pesquisa e Estudos Qualitativos, Bauru, São Paulo, Brasil.

Manzini, E. J. (2012). Uso da entrevista em dissertaçóes e teses produzidas em um programa de pósgraduação em educação. Revista Percurso, 4(2), 149-171.

Manzini, E. J. (2014). Consideraçóes sobre a transcrição de entrevistas. São Carlos: UFSCar/ONEESP. http://www.oneesp.ufscar.br/texto_orientacao_transcricao_entrevista

Masini, E. F. S. (2011). Pesquisas sobre surdocegueira e deficiências Sensoriais Múltiplas. Construção Psicopedagógica, 19(18), 64-72. http://pepsic.bvsalud.org/scielo.php?script=sci_ arttext\&pid=S1415-69542011000100007

Mata, S. P. (2017). Perspectivas de profissionais sobre a trajetória inicial de comunicação de um sujeito com surdocegueira [Dissertação de Mestrado, Faculdade de Filosofia e Ciências, Universidade Estadual Paulista - UNESP]. Repositório da UNESP. https://repositorio.unesp.br/handle/11449/150149

McInnes, J. M. (1999). Deafblindness: a unique disability. In J. M. McInnes (Ed.), A Guide to planning and support for individuals who are deafblind (pp. 3-32). University of Toronto Press.

McLetchie, B. A. B., \& Riggio, M. (2002). Competências para professores de alunos com surdocegueira. In E. F. S. Masini (Org.), Do sentido... pelos sentidos... para o sentido (pp. 145-166). Vetor.

Miles, B., \& McLetchie, B. (2008). Developing concepts with children who are deaf-blind. The National Consortium on Deaf-Blindness. Helen Keller National Center Perkins School for the Blind Teaching Research, 1-8. https://www.nationaldb.org/info-center/developing-concepts-factsheet/

Nunes, L. R. O. P. (2003). Favorecendo o desenvolvimento da comunicação em crianças e jovens com necessidades especiais. Dunya. 
Oliveira, J. P., Rodrigues, E. S., \& Bracken, S. (2017). Suportes para a escolarização de estudantes do público-alvo da Educação Especial. Revista de Estudios e Investigacion en Psicologia y Educación, extra (11), 80-85. https://doi.org/10.17979/reipe.2017.0.11.2415

Reyes, D. A. (2004). La sordoceguera: una discapacidad singular. In D. A. Reyes (Ed.), La sordoceguera: un análisis multidisciplinar (pp. 135-159). ONCE.

Santos, K. S. S., \& Evaristo, F. L. (2015). Mapeamento da produção sobre surdocegueira no Brasil. In M. P. R. Costa, \& R. A. Rangni (Orgs), Surdocegueira: estudos e reflexôes (pp. 56-78). Pedro \& João Editores.

Turiansky, W., \& Bove, M. (1991). Desarrollo de la comunicación. Artículo n² 23. Educación. ONCE.

Van Dijk, J. (1968). Movement and communication with rubella children. Conferência na Reunião Geral Anual da Organização Nacional de Cegos de Madri. ONCE.

Villas-Boas, D. C. (2014). Pessoas com surdocegueira e com deficiência múltipla: análise de relaçóes de comunicação [Tese de Doutorado, Pontifícia Universidade Católica, São Paulo - PUC-SP]. Repositório da PUC-SP. https://sapientia.pucsp.br/handle/handle/11979

Viñas, P. G. (2004). La educación de personas sordociegas. Diferencias y processo de mediación. In P. G. Viñas, \& D. Reyes (Orgs.), La sordoceguera. Um análisis multidisciplinary (pp. 309-362). ONCE.

Von Tetzchener, S. (2018). Introduction to the special issue on aided language processes, development, and use: an international perspective. Augmentative and Alternative Communication, 34(1), 1-15. DOI: 10.1080 / 07434618.2017.1422020

Von Tetzchner, S., Brekke, K. M., Sjathun, B., \& Grindheim, E. (2005). Inclusão de crianças em educação pré-escolar regular utilizando comunicação suplementar e alternativa. Revista Brasileira de Educação Especial, 11(2), 151-184. https://doi.org/10.1590/S1413-65382005000200002

Recebido em: 10/01/2020

Reformulado em: 09/04/2020

Aprovado em: 21/04/2020 
MATA, S.P.; SORIANO, K.R.; OLIVEIRA, J.P. 